\title{
Confianza e integración en Latinoamérica ${ }^{1}$
}

\section{Trust and integration in Latin America}

\author{
Alberto Castillo \\ Universidad EAN \\ acastilloc@universidadean.edu.co
}

\begin{abstract}
Resumen
El objetivo del siguiente artículo es reflexionar en torno a los distintos modelos de integración en América Latina en un escenario de anarquismo regional, en donde impera un carácter marcadamente presidencialista y soberanista que dificulta cada vez más la convergencia de intereses comunes y, por tanto, conlleva la inacción de dichos instrumentos regionales. A partir de la identificación de los elementos constitutivos de la identidad latinoamericana y la diferenciación conceptual entre cooperación, concertación e integración, se incorpora de manera novedosa, el concepto de la confianza como variable interviniente, para así poder establecer de manera inductiva la lógica causal, con el ánimo de reflexionar y proponer una posible respuesta a la pregunta de investigación. El objeto de estudio, por tanto, son los procesos de integración latinoamericanos, no por orden cronológico sino por tipología, de esta manera, se pueden aglutinar actores, procesos y mecanismos que permiten una mejor lectura a la luz de los elementos que hacen parte de los estudios de la confianza en las Relaciones Internacionales. Finalmente, como conclusión se identifica la interdependencia, la congruencia normativa, las percepciones y las metas comunes entre los Estados como algunos de los elementos esenciales a la hora de reducir las complejidades regionales $y$, por otro lado, la hegemonía, la narrativa ideológica, el autonomismo y la incertidumbre como elementos que conducen a la desconfianza dentro de los procesos regionales.
\end{abstract}

Palabras Clave: América Latina; Regionalismo; Integración; Confianza; Relaciones Internacionales.

\begin{abstract}
The objective of the following article is to reflect the different models of integration in Latin America in a scenario of regional anarchism, where a markedly presidential and sovereignist character prevails, making it increasingly difficult for common interests to converge and, therefore, it leads to the inaction of these regional instruments. From the identification of the constituent elements of the Latin American identity and the conceptual differentiation between cooperation, consensus and integration, the concept of trust as an intervening variable is incorporated in a novel way, in order to establish the causal logic in an inductive way, with the intention of reflecting and proposing a possible answer to the research question. The object of study are therefore the Latin American integration processes, not by chronological order but by typology, in this way, actors, processes and mechanisms can be brought together which allows a better reading in light of the elements that are part of the studies of trust in International Relations. Finally, as a conclusion, interdependence, normative congruence, perceptions and common goals among States are identified as some of the essential elements when it comes to reducing regional complexities and, on the other hand, hegemony, ideological narrative, Autonomy and uncertainty as elements that lead to distrust within regional processes.
\end{abstract}

Key Words: Latin America; Regionalism; Integration; Trust; International Relations.

Articulo: Recibido el 26 de junio de 2018 y aprobado el 12 de octubre de 2018

\section{Como citar este articulo:}

Castillo, A. (2019). Confianza e integración en Latinoamérica, Reflexión Política 21 (41), pp. 207-225. DOI: https:// doi.org/10.29375/01240781.3250 Artículo de investigación vinculado al proyecto de investigación "Confianza en las relaciones internacionales del siglo XXI". Agradecimiento a los pares evaluadores por sus sugerentes comentarios y apreciaciones. Las opiniones expresadas en este documento son de exclusiva responsabilidad del autor y no reflejan, necesariamente, los puntos de vista de las instituciones de las que hace parte. 
"Es una idea grandiosa pretender formar de todo el Mundo Nuevo en una sola nación con un solo vínculo que ligue sus partes entre sí y con el todo. Ya que tienen un origen, una lengua, unas costumbres y una religión, debería, por consiguiente, tener un solo gobierno que confederase los diferentes Estados que hayan de formarse; [...]"

Simón Bolivar, Carta de Jamaica (1815)

\section{Introducción}

Las Relaciones Internacionales, desde su nacimiento como disciplina científica, han estado interesadas en dar respuesta a las causas de la guerra y las condiciones para la paz. En este escenario, los desarrollos teóricos racionalistas y reflectivistas han intentado abordar dichos interrogantes desde diferentes enfoques epistemológicos y metodológicos; incluyendo en periodos recientes variables como el medio ambiente, el transnacionalismo, actores no estatales, el cosmopolitismo y hasta la guerra nuclear, entre otros. Es así, como la literatura de las Relaciones Internacionales, a partir de los años 80, ha incluido en su agenda de investigación la confianza como variable interviniente dentro de aquellos condicionantes de la paz como es la cooperación.

La confianza, como campo de estudio en las relaciones internacionales, ha sido desarrollada teóricamente a partir de trabajos clásicos, en un primer momento, a través del análisis de la elección racional con base en la teoría de juegos con trabajos como el de Morton Deutsch (1958), Robert Axelrod (1986), Robert Kehoane (1988) y más recientemente Andrew Kydd (2005). Posteriormente, se procede a incluir el factor humano dentro del análisis de la confianza con autores como March y Olsen (1998), Aaron Hoffman (2002), Ken Booth y Nicholas J. Wheeler (2008), Jan Ruzicka y Nicholas J. Wheeler (2010), Nicholas J. Wheeler (2012), Vicent C. Keating y Jan Ruzicka (2014) y Jan Ruzicka y Vicent Keating (2015).

El siguiente artículo pretende realizar una reflexión entre la confianza y la integración en América Latina dentro de las Relaciones Internacionales como campo científico. A partir de lo anterior, se intentará proponer una posible respuesta a la siguiente pregunta: ¿qué modelo de integración debe asumir América Latina para lograr una cooperación sostenible y perdurable en un escenario de anarquismo regional? Conforme a esta pregunta de investigación, el documento pretende realizar en primer lugar una descripción histórica del establecimiento de la identidad latinoamericana con miras a comprender su narrativa y bases constitutivas de los valores regionales. En segundo lugar, el documento pretende brindar una diferenciación conceptual entre cooperación, concertación e integración para comprender la categoría analítica del trabajo. En tercer lugar, se procederá a realizar un ejercicio analítico con base a las categorías extrapoladas en los desarrollos teóricos de la confianza en las relaciones internacionales sobre los diferentes modelos regionales que estarán clasificados por tipologías, y no cronológicamente, para una mayor comprensión de sus elementos diferenciadores y así, incluir la confianza como variable interviniente en la explicación de los tipos de regionalismo latinoamericano.

\section{Prolegómeno de la construcción de una identidad latinoamericana.}

A partir del planteamiento de Laclau (2008, pp. 91-103) se comprende a la hegemonía como aquella capacidad de universalizar un punto de vista particular buscando resignificar los antagonismos a través de los cuales se construyen las identidades por medio de la diferenciación del discurso. Es allí donde el discurso hegemónico establece una frontera que permite diferenciar al otro a partir de elementos en disputa y que, por tanto, terminan siendo comunes. Así, a partir de lo anterior, se construye el sentido de la identidad política, que nunca se cierra ni se concluye, sino que está en constante disputa y transformación (Franzé, 2015, p. 158).

Ahora bien, si nos remitimos a la construcción de la identidad latinoamericana en estos términos, es imperativo apelar, desde un enfoque foucaultiano, al discurso que se ha generado sobre la base de la diferenciación con otros tipos de discursos hegemónicos que terminan generando significantes y definiendo los valores propios. El proceso de distinción hacia otros modelos permite conformar una sociedad que se fundamenta 
en la exclusión a través de sus propios procesos internos, generando dinámicas de transformación de sus fronteras identitarias y constituyendo la legitimidad entre sus actores internos.

Así pues, cuando se analizan los distintos procesos de integración latinoamericana desde la academia, se suelen extrapolar como referentes interpretativos las categorías del proceso europeo a partir de un enfoque etnocentrista; esto se debe al alto grado de dependencia de las ciencias sociales- y específicamente de las Relaciones Internacionalesen torno a los planteamientos teóricos de Estados Unidos y de Europa (Del Arenal, 2014).

A partir de lo anterior, la construcción de la identidad latinoamericana en una primera etapa parte de la identificación de los factores materiales en relación a la posible distinción con los actores políticos externos, por lo cual, los modelos de acercamiento se han fundamentado en discursos generados a partir de la geografía, la historia, la cultura y la política que han sustentado los movimientos de integración de tinte panamericanistas, panlatinoamericanistas, iberoamericanistas y suramericanistas, entre otros.

Seguidamente, los discursos hegemónicos constitutivos de la identidad regional se han ido transformando a partir de conceptos como raza, cultura o Hispanoamérica a conceptos muchos más complejos y revolucionarios tales como antiimperialismo y Latinoamérica. En este sentido, los valores generales y su significado dentro de la frontera de la comunidad latinoamericana van dotando de mayor relevancia e interpretación a sus distintos valores constitutivos de su propio campo político.

Aunque el término "América Latina" tiene un origen francófono, usado por primera vez en el siglo XIX y que, desde una primera instancia, intentó aglutinar a partir de la lengua latina, ya fuera esta alguna de sus variedades tales como el español, el portugués o el francés, a los países de América del Sur. Desde su concepción, intentó contraponerse a la categoría de Hispanoamérica, propia del Reino español y portugués que aglutinaba a los países americanos de habla española como lengua oficial, incluyendo a Brasil, en coherencia con la idea de la antigua provincia romana Hispania.

Un componente común, presente en casi todos los teóricos y estadistas, ha sido la argumentación en relación con la necesidad de consolidar una integración entre las naciones y sus pueblos, pero, es pertinente hacerse las siguientes preguntas: ¿es importante que América Latina se integre?, ¿es un requisito necesario para su desarrollo? La respuesta a estas preguntas debe darse dentro de cada uno de los contextos históricos presentes dentro del proceso regional latinoamericano; en otras palabras, los procesos de integración no son estáticos, más bien, tienen características fundamentales que los hacen dinámicos $\mathrm{y}$, por tanto, es comprensible que se vayan inclinando hacia un modelo de integración diferente en cada proceso histórico, como puede ser, desde un modelo de naturaleza económica a un modelo más de naturaleza histórico-cultural.

Gustavo Lagos (1967) clasificó dentro de esta evolución histórico conceptual cinco etapas y tendencias de la integración latinoamericana: la primera, se enmarca dentro de la época del movimiento independentista de los países latinoamericanos, en la cual, por ejemplo, la carta de Jamaica de Simón Bolívar inspiraba esa conciencia integracionista, presente en el pensamiento $\mathrm{y}$ visión de los libertadores, pero sin ahondar en una clara estrategia para alcanzarla. La segunda etapa, según el autor, se presentó con el desarrollo y evolución de los nacionalismos latinoamericanos, aproximadamente hasta la primera guerra mundial, en donde se pierde esa conciencia integracionista, se profundiza en la desintegración y fragmentación; sin embargo, va desapareciendo debido a las amenazas externas. La tercera fase, se enmarca entre los años 20 y 70, en donde se empieza a desarrollar una conciencia integracionista a nivel político a través de los vínculos de los partidos políticos y con un sentimiento casi generalizado del discurso antiimperialista, fundamentado en la fortaleza de la unión latinoamericana. El autor señala la cuarta fase como aquella en la cual se logra expresar una conciencia y estrategia de tipo económico, en donde se pueden observar los desarrollos del pensamiento cepalino y empiezan a surgir los primeros modelos de integración, tales como el mercado común centroamericano. Finalmente, la quinta etapa se presenta entre los años 60 y 70, en donde la conciencia integracionista viene permeada por las estrategias internacionales de integración en ámbitos económicos, políticos e intelectuales, es aquí donde surgen modelos como el Pacto Andino y la Asociación Latinoamericana de Integración (ALADI) (Lagos, 1967).

En consecuencia, América Latina ha generado un discurso hegemónico que 
ha permanecido en el tiempo bajo varias interpretaciones, es decir, su objetivo de superación del subdesarrollo y la lucha por su autonomía. Es allí donde la diversidad y la heterogeneidad de los Estados latinoamericanos dificultan en primer lugar, un análisis de manera agregada y, en segundo lugar, la consolidación de una sola voz regional en temas económicos, políticos y sociales.

Conforme a lo anterior, Felipe Herrera (1967), quien fue director del Fondo Monetario Internacional y del Banco Interamericano de Desarrollo, consideraba a América Latina como una gran nación deshecha que puede ser reconstruida a través de la integración como fenómeno político, social, económico y cultural.

En efecto, cabe señalar que el proceso de integración ha terminado permeado por las dinámicas sistémicas internacionales de orden político. Desde un enfoque durkheimiano, funcionalista, se concibe la realidad de los agentes como un resultado de la estructura, a partir de una lógica Top-Down. En el caso de la integración, se podría aludir que el contexto internacional bipolar de la guerra fría, el creciente multilateralismo o la hegemonía norteamericana $\mathrm{u}$ otros tantos fenómenos de orden económico, como son la política económica mundial o las ideologías económicas neoliberales o neokeynesianas han permeado a los procesos integracionistas latinoamericanos.

En una primera instancia, al acabar la segunda guerra mundial, los procesos de integración regional germinaban a lo largo de todo el mundo, tales como la Comunidad Europea del Carbón y el Acero (CECA) en 1952, la Asociación de Naciones del Sureste Asiático (ASEAN) de 1967, la Organización para la Unidad Africana (OUA) de 1963, entre otros. En este contexto de guerra fría, dichas configuraciones regionales respondían a una arquitectura internacional bipolar que reiteraba las prácticas de configuración clásica del regionalismo, es decir, de carácter geopolítico. Así pues, las estructuras regionales intentaban cubrir las necesidades propias e intereses de los actores hegemónicos por medio de alianzas estratégicas para mantener el equilibrio de poderes, en términos teóricos, una clara dinámica del realismo defensivo (Jervis, 1982).

Para tener claridad sobre este tipo de planteamiento, podemos retomar, como uno de los casos más representativos de este tipo de regionalismo geopolítico en el continente americano, la ratificación del Tratado de Asistencia Recíproca
(TIAR) de 1947 y posteriormente, la construcción de la Organización de Estados Americanos (OEA) de 1948. El objetivo de este organismo regional está definido en la conducción hacia la integración, la cooperación y la promoción de la democracia, paz e igualdad de los ciudadanos de sus Estados miembros (Castillo y Brocate, 2013).

De manera que el discurso aglutinador de este tipo de regionalismo se fundamentaba en la prevalencia de la postura de Estados Unidos a través de la Doctrina del Destino Manifiesto (Manifest Destiny), que fue acuñada por los primeros colonos protestantes que llegaron en el Mayflower y que sirvió de sustento al pensamiento republicano estadounidense en la creencia del deber que tenían con todo el mundo en la promoción y defensa de la democracia como sistema de gobierno y de valores.

De ahí que la conciencia doctrinal panamericana se fundamentase en los postulados de la doctrina Monroe, claramente contrapuesta al imperialismo y colonialismo europeo en los territorios americanos a finales del siglo XIX e inicios del siglo XX y, por tanto, buscaba justificar la legitimidad que tenían los Estados Unidos de intervenir en aspectos de América Latina con miras a proteger la independencia territorial del continente.

Ahora bien, la perspectiva latinoamericana, a partir del pensamiento y visión que se recoge de los libertadores; tales como Francisco de Miranda (1750-1816) y Simón Bolívar (1783-1830), consideraba la propia concepción y constitución de naciones independientes y soberanas dentro del escenario internacional como un componente fundamental dentro del proceso de independencia de los territorios hispanoamericanos. Como resultado de dicha visión autonómica se consolidó el proyecto geopolítico regional: la Gran Colombia.

La generación del marco ideacional de una posible identidad latinoamericana se fue gestando, en una primera instancia, a partir de las ideas de Miranda con base en la Gran Reunión Americana, que fue una asociación política gestada en Londres para formalizar la unidad latinoamericana en ese gran territorio de naturaleza republicana con presencia de ciudadanos libres. En definitiva, fue a partir del antagonismo, leído desde la relación dicotómica planteada por Carl Schmitt (1991) de amigo-enemigo, que se gestaron las luchas políticas y militares emprendidas por los Libertadores como Bolívar y Miranda, en territorio hispanoamericano; estas luchas buscaban consolidar un proceso 
integrador que tenía como fin último la conformación de una única nación que compartiese los valores máximos como la religión, la cultura, las costumbres, las tradiciones y, sobre todo, un mismo destino.

\section{Los procesos integradores latinoamericanos: entre cooperación y concertación.}

A partir de la distinción y definición de los valores sobre los cuales se pretende erigir la identidad latinoamericana, el proceso de integración conllevará diferenciar entre las dinámicas de concertación y cooperación.

En primer lugar, la concertación se concibe como la acción en la cual dos o más Estados interactúan conjuntamente dentro de la dimensión político-diplomática (Tokaltian, 1994, p.54). En este sentido, la concertación se fundamenta en el ámbito estrictamente político y sobre la base de relaciones diplomáticas. Es en este escenario, en donde las cumbres regionales tienen relevancia para propiciar espacios de diálogo y concertación de políticas para la resolución de controversias.

Uno de los ejemplos más claros dentro del modelo de concertación en Latinoamérica ha sido el grupo de Contadora de 1983, el cual se constituyó con el objetivo de generar un actor político multilateral que pudiese mediar y dirimir el conflicto centroamericano desde una óptica exclusivamente latinoamericana, es decir, ajena a los Estados Unidos de América, ya que dicho contexto podría escalar hasta desestabilizar la región, por lo cual, se buscaba compartir las reglas comunes, que en ningún caso terminarian siendo neutrales dentro de dicha comunidad. Otro ejemplo, puede ser la Comunidad de Estados Latinoamericanos y Caribeños (CELAC) del 2010 que se retomará en este texto más adelante. En segundo lugar, la cooperación, según el planteamiento de Robert Keohane (1988) "se produce cuando los actores adaptan sus conductas a las preferencias presentes o anticipadas de otros, por medio de coordinación de políticas" (p.74). A partir de lo anterior, se hace necesario un proceso de negociación y una coordinación de políticas entre los actores, en ese orden de ideas, en caso de que exista un conflicto de intereses entre los Estados y éste no se logre resolver podría traer más costos que beneficios. Sin embargo, la cooperación no está exenta de dificultades, los actores deben coordinar sus acciones y, sobre todo, ajustarse a los objetivos comunes, lo que conlleva, muchas veces, dejar de lado los propios intereses y, por tanto, conciliar posturas y visiones diferentes.

Partir del supuesto de que las políticas de los otros Estados están obstaculizando la consecución de las metas propias, avocaría hacia un círculo de acusaciones y críticas que, si bien componen la política, no permiten encontrar puntos en común y escenarios de colaboración. Los Estados cuentan con intereses contrapuestos y otros compartidos; así, dentro de los intereses compartidos podemos encontrar también diferencias en relación al medio o instrumentos que se requerirán para alcanzar el fin; dicho de otro modoe, si bien los objetivos pueden ser los mismos, como puede ser el desarrollo económico de los países, los métodos pueden diferenciarse, tal como sucedió con algunos países latinoamericanos conforme a los postulados cepalinos del modelo de industrialización con sustitución de importaciones (Briceño, 2007, p.49).

Por lo anterior, la identificación de los lugares comunes donde pueden trabajar los Estados es resultado de un proceso de interacción política, intercambios, negociaciones y pugnas que conllevan un alto nivel de comunicación. Así pues, la cooperación debe realizarse dentro de un ámbito de concertación previa, que incorpore cierto tipo de temas o áreas de común interés.

Un ejemplo de lo anterior, puede ser lo que ocurrió en la década de los ochenta entre los presidentes Alfonsín de Argentina y Sarney de Brasil. Ambos propiciaron varios encuentros diplomáticos de alto nivel en donde se desactivaron las percepciones de conflicto tradicionales y abrieron paso a la creación de vínculos bilaterales, como consecuencia condujeron a los mismos a una dimensión de cooperación, fundamentalmente a través del Programa de Integración y Cooperación Argentino-Brasileño (PICAB) que sirvió como base normativa para la consolidación del Mercado Común Suramericano (MERCOSUR).

Finalmente, en cuanto al concepto de integración, desde la literatura académica se fundamentó específicamente dentro de los componentes económicos, por tanto, a menores barreras arancelarias mayor integración había; sin embargo, Juan Gabriel Tokatlian (1954) señala que la integración conlleva un proceso mucho más amplio en el cual se deben incluir una serie de vínculos e interpretaciones sociales, científicas, diplomáticas 
e incluso militares que terminan impactando en la sociedad, en la política y en la economía de los países, por ejemplo mediante la constitución de organismos supranacionales. Por tanto, la integración puede no sólo desarrollarse desde un ámbito económico sino también político e inclusive social.

\section{La confianza dentro del proceso regional latinoamericano}

El estudio de la confianza como variable dentro de la disciplina de las Relaciones Internacionales ha resultado de interés para lograr comprender la construcción de las relaciones pacíficas entre los Estados. Tal como señala Hoffman (2002), la confianza debe ser equiparada con la disposición de asumir riesgos con la expectativa de que los otros harán honor de las obligaciones asumidas; en otras palabras, la confianza implica una actitud que supone poner el destino de los propios intereses bajo el control de los demás. Por lo cual, la relación de confianza permite establecer mecanismos para resolver pacíficamente los problemas entre los Estados por medio de la cooperación que conlleva la reducción de la incertidumbre. De este modo, al desarrollarse las relaciones internacionales en un contexto anárquico, la falta de confianza entre los Estados terminaría incidiendo en la generación de políticas agresivas que conducirían incluso a la guerra, debido al dilema de seguridad (Herz, 1950) que conlleva ese sentimiento de inseguridad generalizado toda vez que el Estado contaría con mayor seguridad en la medida que consiga obtener más poder.

Los procesos regionales suelen establecer compromisos entre los Estados que generan certezas sobre el futuro comportamiento de los mismos; por tanto, la predictibilidad reduce el nivel de actuación aleatoria y, en consecuencia, se establecen expectativas de que los otros harán lo correcto y pactado.

El proceso de regionalismo latinoamericano no ha conllevado al establecimiento de reglas comunes que permitan una mayor libertad de actuación de los Estados, más bien, el proceso de regionalismo latinoamericano puede denominarse como "selectivo" toda vez que carece de obligatoriedad o vinculación normativa entre los Estados. A partir de lo anterior, se puede sugerir la siguiente pregunta: ¿qué estrategia se debe tomar en América Latina para lograr una cooperación sostenible y perdurable en un escenario de anarquismo regional? La respuesta a esta pregunta está vinculada a la consideración de un escenario regional, en donde todos los actores estatales tengan un peso absoluto en las decisiones con base en sus propios intereses y por supuesto, sin contar con algún tipo de institucionalización supranacional regional. Esto conlleva esfuerzos en la generación de medidas de confianza que logren fortalecer los procesos de cooperación e integración.

Nikklas Luhmann (2005) define la confianza como "un mecanismo de reducción de la complejidad que tiene una relación específica con los medios de comunicación simbólicamente generalizados y que adquiere características particulares según se trate de un sistema internacional de una organización o de la sociedad, el ámbito en el cual se despliegue" (p.XXV). A partir de lo anterior, se entiende que la acción de confiar de un Estado es una jugada arriesgada o una inversión atrevida, en la medida en que no se cuenta con la total certeza de que se vaya a obtener un resultado reciproco, ya que se presenta dentro de un marco de interacción que termina siendo influenciado por el agente y por la estructura de manera recíproca, siguiendo la teoría de la estructuración de Anthony Giddens (1995). Por tanto, tal como lo señala Luhmann (2005) la confianza a través de la reducción de la complejidad, "simplifica la vida por medio de la aceptación del riesgo” (pp. 123-124).

En otro sentido, Francis Fukuyama (1996) propone otra definición de la confianza como "la expectativa que surge dentro de una comunidad de comportamiento normal, honesto y cooperativo, basada en normas comunes, compartidas por todos los miembros de dicha comunidad" (p.45). Estas normas comunes se definen en sí mismas como capital social debido a que se establecen dentro de los valores constitutivos o normas informales compartidas de los miembros de un grupo, permitiendo la cooperación entre los mismos, pues no es necesaria la autoridad de una comunidad sino más bien la capacidad de formar nuevas asociaciones y de cooperar dentro del marco de referencia que éstas establecen, lo que Fukuyama (1996, p.46) denomina sociabilidad espontánea.

Algunos autores (Rathbun, 2011; Hoffman, 2007; Hoffman, 2002; Ruzicka \& Wheeler, 2010) han trabajado en el análisis de la confianza dentro de las Relaciones Internacionales y en especial en torno a las dinámicas de la cooperación. A partir 
de estos trabajos se han realizado distinciones de las relaciones de confianza, las cuales pueden variar tanto la intensidad como el alcance de las mismas, por lo tanto, se puede intentar predecir sobre la base de las distintas percepciones los posibles comportamientos; igualmente, se podría basar a partir del conocimiento de la obligación de la contraparte, el cumplimiento con un comportamiento determinado.

América Latina, en sintonía con lo anterior, trabaja en el establecimiento de una cooperación estable por medio del incremento de su confianza, dicho de otr forma, incorpora una actitud que obliga a poner los intereses propios bajo el control de los demás. Este tipo de cálculos no se realizan sobre la base del establecimiento de acuerdos estatutarios marco de la región, sino más bien a partir de un modelo de reciprocidad graduada en la reducción de la tensión o de señalización costosa (Kydd, 2005), por lo cual, se establece la construcción de confianza por medio de dinámicas comunicativas interpersonales que terminan generando empatía y sensibilización de los temas; en otras palabras, se establecen marcos de relacionamiento de los Estados por medio de un lenguaje común. Lograr lo anterior no es una tarea sencilla, puesto que al final implica un salto de fe de los distintos actores, teniendo en cuenta que se trata de un valor intangible que podría aportar a la estabilidad y a la paz en la región.

Thomas Hobbes (1997), determinaba que

(...) de la igualdad procede la desconfianza. De esta igualdad en cuanto a la capacidad se deriva la igualdad de esperanza respecto a la consecución de nuestros fines. Esta es la causa de que, si dos hombres desean la misma cosa y en modo alguno pueden disfrutarlas ambos, se vuelven enemigos $\mathrm{y}$ en el camino que conduce al fin tratan de aniquilarse o sojuzgarse uno a otro. (p.128)

Desde una lectura hobbesiana, en la región latinoamericana se pueden establecer varios intereses contrapuestos entre distintos actores como Brasil, Argentina o México, y no existe un Leviatán o configuración normativa formal para vincular las actuaciones de los mismos, mantener la paz y armonía de los intereses.

En síntesis, la confianza lleva a la cooperación y la desconfianza lleva al conflicto. Supongamos por un momento un posible escenario enmarcado en el dilema de seguridad (Herz, 1950) entre Colombiay Venezuela, en donde Colombia, ante una percepción de amenaza de Venezuela, realiza la compra de armamento para disuadir cualquier tipo de acción probable. Por su lado, Venezuela incrementará su arsenal debido a la necesidad de defensa ante cualquier ataque de Colombia. Este tipo de acción conlleva implícitamente una agresión, pero, sobre todo, implica una latente incertidumbre que hace que los costos de transacción de ambos Estados se incrementen. Este es un claro ejemplo del dilema del prisionero dentro de la teoría de juegos, en donde la cooperación puede obtener como resultado un beneficio conjunto, pero si no se escoge la cooperación, se puede maximizar los beneficios a costa del perjuicio del otro.

Rojas Aravena (2002, p.24) considera a las medidas de confianza mutua como "acciones bilaterales o multilaterales destinadas a prevenir situaciones de crisis y de conflicto. Contribuyen a la comunicación entre actores". Las instituciones del modelo regional latinoamericano se constituyen como precondición para la confianza, pero no son el fin último de la misma. Un elemento esencial para la comprensión de la confianza, que resaltan autores como Elinor Ostrom (2005) y Axelrod (1986), es el de la reciprocidad, en donde los Estados tendrán que recibir respuestas conformes a su propia actuación. Dentro de la lógica sobre la confianza elaborada por Ostrom (2005), se puede concebir la forma en la cual una mayor confianza determina una mayor cooperación, que a su vez incrementa los niveles de reciprocidad positiva y, por tanto, una consolidación de su imagen solida de fiabilidad. Por tanto, un Estado latinoamericano que tenga una alta reciprocidad en torno a las respuestas positivas o de buena voluntad, logrará consolidar una buena imagen o reputación y, así, sus vecinos no dudarán en confiar y consolidar niveles más estrechos de cooperación con este.

Por otra parte, Luhmann (2005) incorpora conceptos como el de riesgo y la incertidumbre a la confianza, tal como lo señala:

El problema de la confianza consiste en el hecho de que el futuro contiene muchas más posibilidades de las que podrán actualizarse en el presente, y del presente transferirse al pasado (...) el hombre tiene que vivir en el presente junto con ese futuro de sobremanera complejo, eternamente (pp. 20-21)

Por lo tanto, deberá reducir la complejidad. La reducción de la complejidad en los 
sistemas sociales se basa en el intercambio de información, el envío de señales, la simetría de sus participantes, la cultura y los principios constitucionales o normativos comunes. A través de este tipo de elementos se puede incrementar la percepción de la confianza. A partir de lo anterior, el hecho de hacer parte de un grupo, denominado América Latina, que comparte una historia, cultura, lengua y religión común, indistintamente de la ideología, hará que se busque realizar alianzas con aquellos actores que inspiran mayor confianza, es decir, con los miembros de una comunidad que compartan sus valores fundamentales, por lo que, no tener un marco significante de valores correspondiente sería una clara señal de desconfianza.

Un ejemplo de lo anterior podría ser un escenario en donde dos Estados se encuentran ante una situación de incertidumbre en torno a si brindar o no confianza para lograr un resultado cooperativo. Se deberá partir de la idea de que la confianza se puede establecer si interviene un actor externo -en nuestro caso debería ser supranacional- que imponga una solución cooperativa. La confianza y la intervención del organismo supranacional se constituirían como la forma de conseguir un fin en sí mismo, el de la cooperación. En el caso de ausencia de dicha estructura regulatoria supranacional, como es el caso latinoamericano, dicha situación permitirá que se avancen y desarrollen procesos de confianza regional, hasta el punto que dicho regionalismo funcione como sustituto de la misma, al generarse un régimen internacional de alcance regional, constituyendo "principios, normas, reglas y procedimientos de toma de decisión, implícitos o explícitos alrededor de los que convergen las expectativas de los actores en un área determinada de las relaciones internacionales" (Krasner, 1983, p.2); es decir, dicha situación liberaría a los Estados miembros de la región de la necesidad de confianza, puesto que en la consolidación de una cooperación multinivel, tal como ocurre en el contexto europeo, resultaría impensable la resolución de las controversias a través de una guerra con los actores regionales.

En las Relaciones Internacionales, se comprende que la situación en la cual los esfuerzos realizados por cada Estado por mejorar su propia seguridad reducen la seguridad de los otros. A esta situación se le suele conocer como "dilema de seguridad” (Herz, 1950; Snyder y Jervis, 1999). El dilema de seguridad puede interpretarse como el juego de la caza del ciervo; un juego que describe un conflicto entre seguridad y cooperación social. JeanJacques Rousseau (2013) describió la situación en donde dos hombres debían elegir cazar un ciervo o una liebre sin el conocimiento del otro. Así es como se aplica el dilema del prisionero que, en el caso del dilema de seguridad, el equilibrio de Nash u óptimo de Pareto resultaría en que ambos jugadores escogen desarmarse y llegar a un acuerdo de paz, pero existe el temor de que, si se desarman unilateralmente, el otro aproveche esta situación para atacar, ya que de esta forma tendrían muchas más oportunidades de aniquilar a su rival. Es aquí en donde se puede comprender la importancia de la comunicación y la coordinación para lograr una maximización de ese equilibrio, ya que, a raíz de dichas acciones, se puede reducir el miedo y la desconfianza que se produciría en este dilema de seguridad. Las dos posibilidades son válidas dentro de las opciones disponibles. Por lo anterior, la construcción de la confianza es una forma de conseguir un resultado cooperativo a través del lanzamiento de señales o símbolos que convenza al otro de ser digno de confianza.

\section{Los modelos de regionalismo latinoamericano}

Para el análisis de la evolución de los procesos de integración y regionalismo en el escenario latinoamericano, se debe tener en cuenta la importancia de la complejidad del sistema internacional que es cada vez más interdependiente (Keohane \& Nye, 2001) y con dinámicas de la globalización que terminan afectando al conjunto de actores regionales.

En la actualidad, optar por la resolución de riesgos y amenazas de forma aislada puede llegar a ser un gran error debido a las distintas implicaciones exógenas que las dinamizan y a los elevados costos que dicha decisión llegaría a suponer. Adicionalmente, los problemas nacionales o locales de un Estado pueden terminar afectando a sus vecinos. Para clarificar este postulado, se toma como ejemplo el contexto colombiano; específicamente el conflicto armado interno que ha ocasionado el desplazamiento de la violencia, el narcotráfico y el crimen organizado a las zonas fronterizas; asimismo, ha generado desplazamiento de ciudadanos a territorios de otros Estados, situaciones que han acentuado la permeabilidad de los riesgos y amenazas. Otro 
ejemplo podría ser la crisis financiera internacional vivida en el 2008 ocasionada por las subprimes en Estados Unidos que se generó dentro de una frontera nacional pero que, a través de las distintas dinámicas de globalización, terminó repercutiendo a diferentes países, especialmente a los europeos, y generando una gran recesión.

Los procesos de integración y regionalismo hacen parte de la propuesta de consolidación de una identidad política común latinoamericana que recoge los cimientos de los procesos independentistas, por lo que se encontrarán como base fundamental en cada uno de los procesos regionales, resaltando sobre todo su autonomía. A continuación, se propone una clasificación de modelos de integración latinoamericanos que se han desarrollado dentro de distintos marcos referenciales identitarios $\mathrm{y}$, con base a los objetivos de las distintas áreas de interés, trascienden las estructuras históricas, a partir de la pretensión de la construcción de un escenario de confianza; en conclusión, se opta por realizar una sistematización a partir de un enfoque tipológico en vez de uno cronológico.

\section{a. Regionalismo geopolitico}

A partir de la identificación de los valores políticos hegemónicos, se puede identificar un primer modelo de regionalismo: el geopolítico. Este tipo de proceso de integración se fundamentará sobre todo en el ideal revolucionario y emancipador con respecto a los antiguos regímenes políticos que sustentaban su poder a través de los vínculos coloniales y en un fuerte componente nacionalista; estos dos elementos estarán presentes en todas las propuestas $\mathrm{y}$ procesos integracionistas latinoamericanos posteriores. A partir de lo anterior, asientan con fuerza las posturas $\mathrm{y}$ visiones compartidas en torno al anti-imperialismo, lo que conlleva un ideal compartido que permitirá la generación de confianza dentro de este tipo de concepción identitaria.

América Latina, con su historia común de colonia, dejó impregnado en su imaginario colectivo el arraigado celo hacia su propia independencia y protección de la soberanía. A pesar de lo que se puede llegar a pensar, el primer modelo de regionalismo geopolítico que se podría tipificar en el hemisferio americano es la Organización de los Estados Americanos (OEA) constituida en el año 1948. Una estructura regional hemisférica que a través de la Doctrina Monroe reiteraba y defendía la protección colectiva del hemisferio de la amenaza extranjera. En dicha configuración hemisférica se promovió previamente el Tratado Interamericano de Asistencia Recíproca (TIAR) suscrito en Rio de Janeiro en 1947, conocido también como Tratado de Rio; este se constituía como un instrumento de defensa colectiva frente a amenazas externas, tal como se expresa en su artículo 3.1:

(...) un ataque armado por parte de cualquier Estado contra un Estado Americano, será considerado como un ataque contra todos los Estados Americanos, y, en consecuencia, cada una de dichas partes contratantes se compromete a ayudar a hacer frente al ataque, en ejercicio del derecho inmanente de legítima defensa individual o colectiva que reconoce el artículo 51 de la carta de las Naciones Unidas (TIAR, 1947, art.3 p.1)

En cualquier caso, las experiencias del regionalismo geopolítico tendrán un desarrollo posterior bastante diverso, ya que romperán con la percepción hemisférica como un todo y se intentará delimitar la frontera política a partir de la idea de la región latinoamericana, apartando el ámbito territorial y político estadounidense de los proyectos regionales posteriores. Dicha situación y el peso desproporcionado del poder de Estados Unidos con respecto a la región, llevará a que se pase de escenarios de confianza a escenarios de desconfianza, toda vez que mutuamente existirán percepciones de instrumentalización hacia los países latinoamericanos desde la potencia hegemónica como desde los actores extrarregionales que podrían llegar a constituirse como una amenaza para sus propios intereses, así como lo expone Andrew Kydd (2005-06) las organizaciones sirven a los intereses de seguridad del hegemón a expensas de las potencias menores, hasta que una de ellas logre ascender en posición y desafiar a dicha potencia. Sin embargo, también la hegemonía promueve la cooperación, debido a que el hegemón construye consenso en torno a un objetivo común, propone la estrategia y supera los problemas de posible ejecución para alcanzar el objetivo.

El viraje dentro de esta tipología de regionalismo se puede comprender bajo la premisa de la consolidación y transformación de Estados Unidos como una potencia mundial y como hegemón regional, en donde sus capacidades materiales no tienen competidor en la región, lo que 
dificulta la diferenciación entre lo que se constituiría como confianza $\mathrm{u}$ otros factores como la coerción o la disuasión debido a la clara heterogeneidad de sus miembros en una posible estabilidad hegemónica regional (Kehoane, 1982). Por tanto, la OEA muestra un claro inmovilismo para aquellos acontecimientos en los cuáles Estados Unidos tiene un gran interés, como la aplicación del principio de no intervención, la participación en la guerra de las Malvinas, la crisis centroamericana, entre otros. Así, se puede comprender la confianza como un mero cálculo de elección racional que, siguiendo el planteamiento de Robert Axelrod (1986) plantearía un dilema al no existir una autoridad central que obligue a cada cual a cooperar con los demás, por lo que la búsqueda del interés propio sería la variable que la racionalidad individual incluiría para determinar su comportamiento. A partir de los atentados del 11 de septiembre en Estados Unidos, la política exterior estadounidense se focalizó en otras regiones del mundo diferentes a la de América Latina. Esto provocó una percepción negativa hacia los Estados Unidos de los países de la región, ya que percibían altos niveles de incertidumbre en la actuación que podría tener hacia ellos, razón por la cual, se alejó de cualquier tipo de consolidación de régimen internacional en la región, dando paso a una percepción de intenciones ofensivas y a las posibles estrategias de respuesta a través de la construcción de poderosas narrativas excluyentes.

\section{b. Regionalismo geoeconómico}

Esta tipología de regionalismo es la que más se ha asociado a la idea de integración. Tras la guerra fría y la caída del muro de Berlín emergieron nuevas dinámicas regionales dentro de la estructura internacional que replantearon aquellas propuestas que habian surgido en un mundo bipolar, pues estas terminaban respondiendo a otro tipo de necesidades y en el nuevo contexto la inserción internacional a través de un fuerte componente económico era la preferencia de los actores estatales. Es así como se priorizó una ruta basada en la apertura externa y especialmente cimentada en los lineamientos del Consenso de Washington.

La Comisión Económica para América Latina y el Caribe (CEPAL) consideró este tipo de regionalismo como "Regionalismo Abierto", es decir, una integración regional llevada a cabo en un ambiente de liberalización y desreglamentación que, por tanto, era compatible y complementaria con la liberalización multilateral (CEPAL, 1994).

Este tipo de regionalismo, parte del supuesto de la necesidad de asumir una estrategia multilateral en torno a la inserción al mercado internacional. Así pues, solo a través de la cooperación económica entre los Estados se puede hacer frente a los procesos de globalización, reduciendo los costos y, a su vez, ampliando el mercado a partir de una mayor incidencia en la interdependencia de los Estados miembros.

José Antonio Sanahuja (2010) señala que el "regionalismo se configuró como un instrumento para respaldar las capacidades de gobiernos a través de la acción regional" (p.459). Esta afirmación, nos brinda una idea de la instrumentalización que da el Estado a los procesos de regionalización para lograr mayor incidencia y, sobre todo, la aglutinación de un discurso predominante y hegemónico que terminó homogeneizando las prácticas de sus diferentes actores.

Las propuestas regionales que se podrían enmarcar dentro de este modelo de regionalismo geoeconómico son: el Tratado de libre comercio de América del Norte (TLCAN) desde 1992, el sistema de integración centroamericano (SICA) desde 1991, la Comunidad Andina de Naciones (CAN) desde 1996 , el Mercado Común del Sur (MERCOSUR) desde 1991 y de reciente creación, la Alianza del Pacífico desde 2011.

Los dos bloques económicos subregionales suramericanos -léase la CAN y MERCOSUR- en 2008 llegaban a constituir un 90\% de su comercio a partir de una postura libre de aranceles. En consecuencia, la idea que se consolidaba de un Área de Libre Comercio de Suramérica (ALCSA) fraguada en 1993, impulsaba una concepción de integración económica en óptica suramericana. Es, en la primera reunión de presidentes de América del Sur realizada el 31 de agosto de 2000 en Brasilia, en donde se intentó encauzar los dos bloques subregionales dentro del ALCSA toda vez que se matizaba la necesidad de avanzar en el entendimiento y armonía de los actores, la voluntad de consolidación y el respeto a la democracia representativa; así pues, se sentaron las bases políticas para la interconectividad física de la región

2 La comunidad andina fue fundada en 1969 con el acuerdo de Cartagena, pero fue en 1996 con el acta de Trujillo que se elabora el protocolo modificatorio que crea la Comunidad Andina y establece el Sistema Andino de Integración. 
al plantearse la iniciativa para la Integración de la Infraestructura Regional de Suramérica (IIRSA), la cual entró en vigor en diciembre de ese mismo año.

El regionalismo abierto produjo un crecimiento considerable dentro de las relaciones intrarregionales; se estima, según datos de la CEPAL (2010), que entre el año 1990 y 2000 las exportaciones de Latinoamérica hacia su propia región estaban en una tasa anual del $14.4 \%$ y entre 2000 y 2008 del $15.2 \%$.

Según la categorización clásica de integración de Jan Tinbergen (1965) se puede distinguir entre integración negativa e integración positiva. En la primera, se hace énfasis en la supresión de todas aquellas barreras que interfieren en las economías, como pueden llegar a ser los aranceles u otras barreras comerciales. En cambio, cuando nos referimos a la integración positiva ponemos nuestra atención a la inclusión de formas de cooperación entre sus políticas macroeconómicas y aquellas políticas que dinamicen la competitividad internacional. Es por esto que, una integración positiva constituirá la creación de un marco supranacional, en donde los Estados nacionales cedan parte de su soberanía a favor de la cooperación que irá más allá de lo meramente económico.

Algunos Estados, como México, Chile, Perú y Colombia asumieron una estrategia radial "hub and spoke" para perseguir sus propios intereses estratégicos $\mathrm{y}$, por tanto, focalizar sus esfuerzos en realizar alianzas de manera unilateral con otros actores externos (Sanahuja, 2016). Por lo anterior, se puede comprender la proliferación en estos países de acuerdos bilaterales de libre comercio con diferentes actores extrarregionales, como pueden ser los realizados con Estados Unidos o la Unión Europea, a diferencia de una posible negociación desde una perspectiva regional.

Como se puede observar en la cartografía latinoamericana, nos encontramos en un escenario de solapamiento de las diferentes estructuras regionales en Latinoamérica (Nolte, 2014), por tanto, el nivel de eficiencia, efectividad e impacto se termina cuestionando. Por lo anterior, se habla de un agotamiento del regionalismo abierto debido a su actuación parcializada y selectiva que no ha logrado, en primer lugar, alcanzar sus objetivos económicos, y en segundo lugar, no ha logrado matizar los aspectos políticos y sociales. Uno de los aspectos cruciales dentro de este posible agotamiento es el marcado nacionalismo y protección de la soberanía nacional que ha impedido desde sus orígenes, una consolidación de la dimensión institucional propia, por lo cual, se dejó a un lado cualquier idea de proyecto de consolidación de estructura supranacional con órganos comunes, con atribuciones soberanas para tomar decisiones mancomunadas, más bien, como algunos autores (Fawcett \& Serrano, 2005; Nolte, 2014) señalan se trataría del establecimiento de una gobernanza regional latinoamericana.

Las críticas que se generan en torno al regionalismo latinoamericano responden a varias motivaciones tales como: i) la heterogeneidad de los Estados latinoamericanos, en especial, a partir de sus capacidades materiales expresadas en extensión de su territorio, recursos naturales y energéticos, crecimiento de la economía, número de habitantes y capacidad militar. De esta forma, muchos de los procesos regionales han sido apalancados por las estrategias e intereses que se promulgan desde dichos actores que cuentan con un gran poder en este tipo de categorías, como puede ser el caso de Brasil, Venezuela o Chile. ii) La presencia de Estados pivotes geográficos de Estados Unidos, cuya influencia, bien sea geográfica o de poder, incide en las dinámicas regionales. Un ejemplo de este tipo de factor es la cercanía geográfica de México, y en general de Centroamérica, con los Estados Unidos; lo anterior ha generado que aquellos países tengan que incluir la variable de permeabilidad de su vecino del norte dentro de las dinámicas integracionistas y sus lógicas relacionales. En este sentido, prima la relación estratégica con Estados Unidos y no con los países de Latinoamérica. iii) $\mathrm{El}$ excesivo nacionalismo y su política exterior como política de gobierno, en cabeza de su presidente en detrimento de una política de Estado, promueve la prevalencia de una integración regional intergubernamental.

Las continuas y aceleradas dinámicas internacionales han propiciado y continúan propiciando un desplazamiento del poder del Atlántico al Pacífico (Castillo, 2013; Barbé, 2012; O'Neill, 2001; Amsden, 2001) y también del norte al sur del mundo. A partir de un enfoque de la Economía Política Internacional (EPI) nos encontramos ante un escenario en donde emergen nuevos mercados internacionales y alianzas bajo la premisa de establecer nuevas dinámicas comerciales, como sucede con los BRICS (Brasil, Rusia, India, China y Sudáfrica). Sin embargo, la 
narrativa de una fractura entre atlántico y pacífico en Latinoamérica es simplista y no contempla las múltiples agendas del proceso de integración regional a partir de la cooperación sectorial y concertación política (Sanahuja, 2016).

El peso cada vez mayor de los mercados asiáticos en América Latina ha cuestionado la fortaleza de los procesos regionales, ya que a partir de una lógica utilitarista benthamiana se llevaron a cabo acercamientos para dotar de materias primas al gigante de oriente. Esto ha permitido que los países latinoamericanos focalicen sus exportaciones específicamente en commodities. De igual forma, este acercamiento no se realiza sobre la base de una condicionalidad basada en el respeto a los Derechos Humanos o sobre la base de imperativos morales, más bien, se genera a partir del pragmatismo que resulta de la política exterior de países como China, por lo cual, es poco relevante qué tipo de gobierno tenga instaurado el socio latinoamericano, lo importante es maximizar la rentabilidad de las ganancias y lograr dotarse de materias primas para alimentar a su población.

Adicionalmente, la fragmentación del poder de norte al sur del mundo está incorporando dinámicas propias a la sociedad internacional, tales como, la férrea defensa de la soberanía nacional y la no injerencia en los asuntos propios como principio fundamental. Sin embargo, cabe resaltar que el surgimiento de partidos de extrema derecha en el norte también está contando con dichas dinámicas nacionalistas y proteccionistas. Por lo anterior, este tipo de soberanía westafliana se contrapone a la lógica posmoderna, superadora de la idea de frontera y soberanía clásica, inscrita en el modelo de gobernanza cosmopolita (Archibugi y Held, 1995). Uno de los puntos comunes en todos los procesos integracionistas y regionales en América Latina, bien sea a través de sus tratados constitutivos o a partir de la diplomacia de las cumbres es el irrestricto respecto a la soberanía nacional y la no injerencia en los asuntos internos de los países.

En esta tipología de regionalismo, la anarquía, entendida como aquella ausencia de legitima autoridad suprema, se supera debido a los grandes niveles de interdependencia compleja que presenta la cooperación económica latinoamericana, haciendo que el costo de la deserción sea mucho mayor que el de la cooperación, toda vez que las sociedades como exponen Keohane y Nye (2001) se conectan a través de múltiples canales sean estos interestatales, transgubernamentales o trasnacionales, desarrollan una agenda que comprenden diferentes ámbitos de trabajo que trasciende los ámbitos político-militares y, la por tanto, la fuerza militar no se usa para la resolución de los conflictos dentro de la región (p. 20-28). A partir de lo anterior, el constante flujo de información por los crecientes niveles de intercambio económico conlleva un comportamiento predecible según la madurez de la relación establecida mediante la interdependencia compleja. Así las cosas, la incertidumbre y la anarquía se reducen conforme al mayor vinculo económico que se genere entre las partes, de tal manera que la condición estructural implica una incidencia en el comportamiento de los actores miembros de la región y, por último, se empiezan a producir expectativas de respuesta en una cooperación recíproca, lo que provoca una generación de mayor confianza en torno a las expectativas de los diferentes actores.

\section{c. Regionalismo geosocietal}

América Latina ha girado ideológicamente hacia un horizonte común y con ello nuevos vientos de integración y regionalismo empezaron a surgir. Los proyectos de integración no resultaron ser contrapuestos a los existentes, pero tampoco se ubicarondentrodeunalógica decomplementariedad (Castillo \& Brocate, 2013). Algunos autores (Motta y Ríos, 2007; Sanahuja, 2010; 2012) han denominado a este tipo de regionalismo como posliberal, ya que dicho regionalismo ha logrado superar el debate del regionalismo abierto e incluir en su análisis el desarrollo explicativo de la estructura sobre el agente.

Este regionalismo posliberal tiene connotaciones del tipo de integración positiva toda vez que logra brindar una redefinición de la región a partir de elementos más políticos, sociales y culturales, en donde el rol de las ideas y las normas va moldeando las actuaciones de sus estados miembros sobre la base de una cierta identidad e intereses compartidos, es decir, pone su énfasis en las low politics regionales. Los ejemplos más característicos de este tipo de regionalismo posliberal son la Alianza Bolivariana de los Pueblos de América (ALBA) desde el 2004, la Unión de Naciones Suramericanas (UNASUR) desde 2008 y la Comunidad de Estados de América Latina y el Caribe (CELAC) desde 2010. 
A partir del agotamiento, más no la supresión del regionalismo abierto, se gestó de manera diferenciada un proceso de integración que podría tipificarse como regionalismo geosocietal; que si bien, este desarrollo regional ha estado marcado por el debate epistemológico entre hegemonía, poshegemonía, neoliberalismo y posliberalismo (Briceño, 2016), asimismo, se han realizado aportes desde la academia para la comprensión y tratamiento del concepto de Regionalismo Posliberal (Sanahuja, 2009) y del concepto de regionalismo Poshegemónico (Tussie y Riggirozzi, 2012). Dichos desarrollos teóricos parten de la diferenciación del neoliberalismo como proyecto hegemónico de Estados Unidos, por un lado, y por el otro, como el fin de una era del regionalismo abierto fundamentado en la liberalización del comercio. En este sentido, más allá de la exclusión explicativa del componente hegemónico y neoliberal, la inclusión de la dimensión política y social en este modelo de regionalismo latinoamericano ha permeado los discursos a partir de la homogeneización de la narrativa contrahegemónica. En este sentido, la concepción hegemónica en el orden mundial propuesta por Robert Cox (1981, pp.136-137) quien retoma la base epistemológica de Antonio Gramsci, la enmarca en estructuras históricas en las que intervienen tres tipos de fuerzas; capacidades materiales, ideas e instituciones, que interactúan entre sí generando las relaciones de poder en la coerción o consentimiento de las acciones. Un elemento dentro de esta tipología de regionalismo es la fuerza de las ideas que generan visiones compartidas y expectativas de conducta de los diferentes actores conforme a las relaciones de poder. Por lo anterior, la tipología de regionalismo geosocietal podría comprender la totalidad de los procesos regionales que se han generado en América Latina desde el siglo XXI, incluyendo así, la superación del componente neoliberal del regionalismo abierto como también la comprensión de un proceso adicional en los campos políticos.

Para entender mejor esta tipología de regionalismo, se retomará y extrapolará al análisis el concepto de "campo político" de Pierre Bourdieu (2001), puesto que, para intentar comprender la sociedad latinoamericana, se debe tomar en consideración como un sistema complejo -integrado por diversos campos políticos- de los que hacen parte el económico, el social, el cultural, el jurídico, el político y el científico.
El regionalismo latinoamericano está intentando constituirse como un campo político en donde se establezcan unos límites internos y externos. Por lo tanto, no debería generarse una exclusión de uno de los campos como puede ser el económico, sino que, más bien, se debe trabajar desde la lógica interna que intenta proponer una interpretación contrahegemónica a partir del establecimiento de una autoridad legítima con miras a generar unas reglas propias conforme al sentido de nuevos valores. En otras palabras, se presenta una lucha política en la región para establecer cuáles serán esos valores y, por tanto, cuál será el sentido del establecimiento de las reglas que generarán un orden legítimo de la sociedad latinoamericana.

Los proyectos de regionalismo geosocietal que se planearon desde Venezuela o Brasil son totalmente diferentes. En primer lugar, debido a los valores que establecieron cada uno de los agentes por medio de la jerarquización de la autoridad que tenían en cada proceso, más aún, cuando se interesaban por autoproclamarse como potencia normativa en la región. En segundo lugar, priorizando una agenda política conforme a dichos valores que establecían una clara diferenciación con los actores extrarregionales.

El proceso de consolidación de la Unión de Naciones Suramericanas (UNASUR) tuvo lugar en la tercera reunión celebrada en Cuzco - Perú el 8 de diciembre de 2004. Allí se declaró el surgimiento de la Comunidad Suramericana de Naciones (CSN) y se activaron las tres líneas de actuación del proyecto suramericano: la conformación, la integración y la acción. La primera línea focaliza su importancia en la convergencia y conformación de intereses y valores compartidos afirmando a Suramérica como un grupo regional a través de "la convergencia de sus intereses políticos, económicos, sociales, culturales y de seguridad como un factor potencial de fortalecimiento y desarrollo de sus capacidades internas para su mejor inserción internacional" (CSN, 2004, p.1). La segunda línea hace mención a la profundización de la convergencia del MERCOSUR, CAN y Chile en el Área de Libre Comercio de Suramérica (ALCSA), además de buscar "la integración física, energética y de comunicaciones en Suramérica sobre la base de la profundización de las experiencias bilaterales, regionales y subregionales existentes, con la consideración de mecanismos financieros innovadores y las propuestas sectoriales en curso que permitan una mejor realización 
de inversiones en infraestructura física para la región" (CSN, 2004, p.2); todo esto a través de la Iniciativa para la Integración de la Infraestructura Regional Suramericana (IIRSA). Y, por último, la promoción de la convergencia de acciones a través de la institucionalidad existente de la CSN evita la superposición y duplicación de esfuerzos.

Luego, en Brasilia, el 30 de septiembre de 2005 se llevó a cabo la primera reunión de jefes de Estado de la CSN en donde se estableció una agenda prioritaria para buscar reducir las asimetrías en los procesos de integración a partir de las áreas del "diálogo político, la integración física, el medio ambiente, la integración energética, los mecanismos financieros suramericanos, las asimetrías, la promoción de la cohesión social, de la inclusión social y de la justicia social y las telecomunicaciones" (CSN, 2005, p.1).

Posteriormente, en la segunda reunión de jefes de Estado de la CSN realizada en Cochabamba en el2006 se proyectó un nuevo modelo deintegración para Suramérica con la incorporación de seis principios rectores para fortalecer la integración; son los siguientes: (i) la solidaridad y cooperación para lograr una mayor equidad, reducir la pobreza y disminuir las asimetrías; (ii) soberanía, respeto a la integridad territorial y autodeterminación de los pueblos según los principios de las Naciones Unidas; (iii) paz y resolución pacífica de las controversias; (iv) democracia y pluralismo en contraposición a las dictaduras y con respeto a los derechos humanos y de las minorías; (v) el carácter universal, interdependiente indivisible de los derechos humanos; (vi) armonía con la naturaleza para un desarrollo sostenible (CSN, 2006).

A partir de la I Cumbre energética de Isla Margarita del 17 de abril de 2007 se adoptó la creación de una integración de carácter energético y, además, se acuñó el nuevo nombre para la CSN que pasaría desde entonces a denominarse Unión de Naciones Suramericanas (UNASUR), la cual contaría con una sede permanente en Quito (Ecuador) y un secretario general ${ }^{3}$. A partir de la III reunión de jefes y jefas de Estado de los 12 Estados miembros, realizada el 23 de mayo de 2008, se formalizó el uso de UNASUR y su tratado constitutivo comenzó a tener plena vigencia desde el día 11 de marzo de 2011 en la localidad de Mitad del Mundo en Quito (Ecuador) cuando se logró obtener la mínima cuota de ratificaciones.

El tratado constitutivo de la UNASUR apuesta abiertamente a una concepción política del regionalismo, alejándose de anteriores modelos de integración; es por esto que se hace una simple mención en el preámbulo en donde se anima a incluir y aprovechar los logros y avances de los bloques económicos subregionales como los de la CAN y MERCOSUR.

A partir de sus artículos, el tratado constitutivo de la UNASUR de 2011 establece que se dotará de personalidad jurídica, y señala como su objetivo general la construcción de un espacio de integración y unión a través del diálogo político y políticas en diversas áreas para fortalecer la democracia y reducir las asimetrías en el marco del fortalecimiento de la soberanía e independencia de los Estados. Asimismo, señala sus objetivos específicos tales como:

la protección de la biodiversidad, recursos hídricos y los ecosistemas, integración financiera, desarrollo de infraestructura, integración, superación de las asimetrías, fortalecimiento del diálogo político, desarrollo social y humano con equidad e inclusión, erradicación del analfabetismo, consolidación de una identidad suramericana, cooperación en materia de migración, acceso universal a la seguridad social y a los servicios de salud, promoción de la diversidad cultural, implementación de políticas en investigación y tecnologías, integración industrial y productiva (UNASUR, 2011, pp.9-12)

La UNASUR, tomando en consideración sus objetivos propuestos, logra dilucidar la voluntad de integración de los países suramericanos. En cierto modo y de forma natural, muchos de sus intereses terminan convergiendo cada vez más, y esto no es extraño, puesto que, además de su sintonía lingüística y cercanía geográfica, comparten también un fuerte componente religioso dentro de su estructura social; en adición, sus índices de desigualdad son altos, son productores en su mayoría de materias primas y el presidencialismo marca su sistema político. Se puede también leer que la convergencia de dichos intereses responde a la propia concepción de países que, como Brasil,

3 Los secretarios generales en UNASUR hasta el momento han sido: Néstor Kirchner (4 de mayo de 2010 al 27 de octubre de 2010), María Emma Mejía (9 de mayo de 2011 al 11 de junio de 2012), Alí Rodríguez Araque (11 de junio de 2012 al 1 de agosto de 2014) y Ernesto Samper Pizano (del 22 de agosto de 2014 al 31 de enero de 2017). 
quieren incorporarse internacionalmente a partir de la ampliación de sus mercados y la posibilidad de acceso al Pacífico para lograr incrementar sus beneficios económicos al igual que políticos.

El liderazgo brasileño en la región puede servirle de plataforma de lanzamiento para una posible actuación a nivel internacional. En cualquier caso, la estructura regional a partir de procesos de confianza genera mayor estabilidad a la región, ya que las actuaciones de los miembros contarán con una mayor previsibilidad y la resolución de las controversias girará en torno a esta institución multilateral, por lo cual, sirve de base para un modelo de gobernanza democrática regional.

Dentro de los más recientes modelos regionales latinoamericanos se encuentra la Comunidad de Estados Latinoamericanos y caribeños (CELAC) que se estableció formalmente en diciembre de 2011 en la III Cumbre de Jefes de Estado y de Gobierno celebrada en Caracas, Venezuela. Esta organización, a diferencia de la UNASUR, no cuenta con un andamiaje institucional, carece de órganos administrativos, sus decisiones se adoptan por consenso y su instancia suprema es la Cumbre de Jefes de Estado y de Gobierno que se reúne anualmente en el país que ostente la presidencia pro témpore. La I Cumbre se realizó en Santiago de Chile en el mes de enero de 2013; la II Cumbre se realizó en La Habana, Cuba en 2014 donde se proclamó a Latinoamérica como zona de paz; la III Cumbre realizada en San José, Costa Rica, permitió poner a debate la oportunidad de reflexionar sobre la seguridad alimentaria; finalmente, la IV Cumbre fue realizada en Quito, Ecuador, el debate contó con una agenda muy amplia que abarcó distintas áreas tales como terrorismo, turismo, corrupción, energía y paz, entre otros.

La CELAC cuenta con 33 países miembros que se constituyen como un

mecanismo de diálogo y concertación de países de América Latina y el Caribe, es la más alta expresión de la voluntad de unidad en la diversidad, donde en lo sucesivo se fortalecerá los vínculos políticos, económicos, sociales y culturales sobre la base de una agenda común de bienestar, paz y seguridad para nuestros pueblos, a objeto de consolidarse como una comunidad regional. (CELAC, 2011, p.4)

La fundamentación de la CELAC se erige en la necesidad de estimular un espacio propiamente latinoamericano, en donde los países puedan concertar políticas regionales. Del mismo modo, es el resultado del marcado desinterés hacia las cumbres iberoamericanas y de la necesidad de forjarse como un interlocutor organizado reconocido ante la Unión Europea. Dentro de las críticas que pueden encontrarse en esta iniciativa regional se encuentra el excesivo peso de la figura del presidente, sea Jefe de Estado o de Gobierno, en estas cumbres. La CELAC busca la recuperación de la unidad latinoamericana, la identidad común desde la comprensión de la diversidad de visiones y estrategias políticas, económicas y sociales. Este espacio de diálogo no se presenta como un reemplazo a la OEA, UNASUR, MERCOSUR, SICA o CAN; además, no cuenta con un desarrollo institucional que pueda formalizar las distintas iniciativas y propuestas, por lo tanto, ahora solo cuenta con un alcance político.

La confianza dentro de esta tipología de regionalismo se torna más compleja de abarcar, ya que se espera que el comportamiento de los Estados sea coherente con lo que es correcto por la estructura social y, por lo tanto, los demás corresponderán recíprocamente ante este comportamiento. Ahora bien, existe el riesgo de encontrar comportamientos diferentes a los previstos, pues la incertidumbre y la vulnerabilidad por la falta de obligación supone un riesgo en este tipo de relaciones. América Latina cuenta con países que, debido a la cercanía con Estados Unidos, como es el caso de Colombia y México, pueden generar una falta de previsibilidad de sus comportamientos y una interpretación sesgada de sus actuaciones, asimismo, países como Brasil o Venezuela, pueden instrumentalizar e imponer una serie de narrativas en la región con el objetivo de cambiar el marco referencial ideacional, proyectando sus intereses en la inserción internacional. La generación de los campos políticos en esta tipología de regionalismo dificulta y genera desconfianza en el establecimiento de los límites entre lo interno y lo externo, en la consolidación de la identidad política regional $\mathrm{y}$, finalmente, la ausencia de un liderazgo en la región.

La existencia de una sociedad de Estados latinoamericanos está supeditada a la conciencia de tener ciertos intereses y valores comunes, en otras palabras, que esté fundamentada por un mismo conjunto de reglas en la regulación de sus relaciones y compartan el funcionamiento de unas instituciones comunes (Bull, 2005). A partir de la óptica Kantiana se establece que las 
relaciones internacionales se fundamentan en el establecimiento de lazos sociales trasnacionales que unen a los individuos de nacionalidades diferentes, por lo cual, más allá de los procesos regionales latinoamericanos, está tomando cada vez más valor la idea de que el Estado va perdiendo relevancia frente al individuo. Al compartir valores y principios dentro de una misma región, los intereses de todos los individuos serán los mismos, en consecuencia, la característica es que se brinde un marco de cooperación puro, dictado por imperativos morales. El punto final sería la consolidación de un mundo cosmopolita en donde los Estados no sean indispensables para el ordenamiento. En este sentido, el transnacionalismo ve al mundo como una enorme telaraña en donde todos estamos interconectados y nos encontramos en un mundo filosóficamente fundamentado a partir de la tradición grociana, en la cual los intereses mutuos generan cierto orden regional e internacional. Sin embargo, en América Latina, los intereses responden a dos tipos de planteamientos ideacionales; los hegemónicos y los contrahegemónicos que, actualmente se encuentran en pugna, haciendo que dicho proceso de integración intente definir los limites entre el "nosotros" y "ellos". Lo anterior, ha dado como resultado que en el año 2018 cinco grandes países de Suramérica (Argentina, Brasil, Chile, Paraguay y Perú) decidieran suspender su participación en el organismo y Colombia haya decidido retirarse de UNASUR.

\section{Conclusiones}

En América Latina se debe trabajar en las medidas de confianza que establezcan sus diferentes Estados, pues existen dinámicas que generan desconfianza entre los mismos, tales como los símbolos lingüísticos ambiguos que brindan una interpretación errónea de sus actuaciones, el dilema de seguridad, la percepción difusa entre actitudes ofensivas $\mathrm{y}$ defensivas $\mathrm{y}$ el fundamentalismo ideológico que nutre igualmente la incertidumbre del futuro. Los países latinoamericanos deben optar por trabajar en incrementar las expectativas y predictibilidad de las acciones de sus vecinos, más que servir como potenciadores de inestabilidad en la región. La confianza es susceptible a variación según su alcance e intensidad de dichas relaciones. La intensidad se refiere a la fuerza de percepción de un actor de la fiabilidad de los demás.
Luego de este recorrido analítico, se puede inferir de manera muy preliminar que no existen variables institucionales formalizadas que incluyan mecanismos regionales sancionatorios institucionalizados para generar un patrón de comportamiento estándar. A partir de lo anterior, debido a que el costo del incumplimiento de una acción que genera desconfianza no es elevado, se incrementan de manera exponencial este tipo de comportamientos.

La creciente interdependencia de los Estados latinoamericanos hace que cada vez sea más costosa la actuación unilateral y en perjuicio de los demás. Según Celestino del Arenal (2002) existen diferentes postulados dentro del paradigma trasnacional como pueden ser los constantes cambios, la cooperación y la interdependencia han transformado el escenario internacional en una sociedad mundial. Se han generado nuevos problemas y además de eso se han establecido nuevos valores e intereses comunes. Los modelos ya no solo responden a factores culturales, tecnológicos y económicos que estrictamente políticos. El debilitamiento del papel del Estado como entidad soberana y estructura capaz de garantizar el bienestar y seguridad de sus ciudadanos y se difumina la separación entre cuestiones internas y externas. Los Estados cada vez más se abren al exterior, por tanto, a través de este efecto se ha dado un debilitamiento a las fronteras estatales.

En este sentido, América latina, específicamente sus gobernantes, siguen vinculados a concepciones tradicionales del ordenamiento internacional, se quedan en la retórica y poco se avanza en elementos vinculantes que permitan reducir las incertidumbres. Los ciudadanos latinoamericanos a través del establecimiento de enlaces cada vez más fuertes y el abordaje de los temas que trascienden las fronteras constituyen ámbitos de mayor cooperación y legitimidad de sus acciones. Este tipo de acercamiento es natural debido a que se establecen en ámbitos de grupos cerrados donde la similitud de los valores y cultura dotan de la información necesaria para una manifiesta confianza.

Adicionalmente, cabe señalar que el proceso de confianza que se propicia a partir del proceso del regionalismo latinoamericano está fuertemente marcado por la identidad cultural e histórica, por medio de la colaboración sobre puntos específicos; no existe un reconocimiento de una autoridad que pueda garantizar y supervisar 
los resultados propuestos. A partir de lo anterior, se llevan a cabo acciones de colaboración por medio de la concertación que no generan elementos de confianza que mitiguen las incertidumbres e incrementen las probabilidades de las certezas; en esta consecuencia, se puede presentar el oportunismo al corto plazo como se denomina en economía el problema del polizón.

La no existencia de reglas comunes puede provocar el dilema de la interpretación y de respuesta; a partir de las acciones que desarrolle un actor puede llegar a interpretarse como ofensivas o defensivas, generando una imagen o percepción errónea que podría generar una respuesta hostil (Jervis, 1976). Del mismo modo, a priori, tomando en consideración la heterogeneidad de identidades políticas de los Estados latinoamericanos, puede generarse lo que Ole Holsti (1962) denominó el modelo de mala fe inherente. En otras palabras, a partir de un fundamentalismo ideológico se asigna el estatus de enemigo y de amenaza a otro Estado debido a su identidad política, más que a su comportamiento internacional que puede revertir dicha percepción.

América Latina ha desarrollado acciones que impulsan la confianza desde algunas áreas específicas como el comercio internacional, infraestructura y el sistema político democrático. Estas han logrado permear de manera positiva los otros escenarios, pero, en cualquier caso, existe una sensibilidad muy alta en torno a temas como la seguridad, los derechos humanos, la economía y el medio ambiente, que se encuentran latentes y en un escenario de apaciguamiento identitario.

Las diferentes tipologías de regionalismo que se han llevado a cabo en América Latina han contribuido a la generación de intercambio de información y escenarios de reducción de complejidad regional; sin embargo, dichos procesos regionales también han mostrado una clara fragmentación en las identidades de los distintos países, en donde el más claro ejemplo ha sido el regionalismo geopolítico y societal que no fue capaz de articular valores comunes en una narrativa hegemónica; por el contrario, estableció una fragmentación interna que aunada a la falta de liderazgo conllevó a su inacción y crisis institucional, por tanto, la generación de múltiples respuestas para problemas comunes y compartidos. El regionalismo geoeconómico, por otro lado, debido a la creciente interdependencia y generación de vínculos trasnacionales, ha permitido lograr un mayor alcance entre los Estados debido a la confianza que desde los ámbitos económicos se alcanza a lograr. Así, esta misma, se traspasa a otros sectores en relación con la empatía y predictibilidad del comportamiento; también sucede de esta manera por el incremento de los costos que un comportamiento no correcto podría conllevar. El problema en este tipo de regionalismo en América Latina, es que se encuentra a nivel subregional y aunque es posible ampliarse, aún existe una clara diferenciación y percepción entre la zona andina y el cono sur. Este último ha logrado constituirse como un régimen internacional de carácter regional; el otro está inmerso en problemas de gobernabilidad que genera problemas de coordinación que no se resuelven y calculan racionalmente con la delegación de funciones a instituciones y normas de carácter regional que, más bien, terminan permeando sus limitaciones a las mismas.

\section{Referencias}

Amsden, A. (2001). The Rise of 'the Rest': Challenges to the West from Late-Industrializing Economies. New York: Oxford University Press.

Archibugi, D., \& Held, D. (eds.) (1995). Cosmopolitan democracy: an agenda for a new world order. Oxford: Polity Press.

Axelrod, R. (1986). La evolución de la cooperación: el dilema del prisionero y la teoría de juegos. Madrid: Alianza Editorial.

Barbé, E. (2012). La UE frente a la emergencia de un mundo posoccidental: en busca del prestigio. Revista cidb d'Afers Internacionals, 100, pp. 91-112.

Bernal, M (2005). América Latina en el mundo: el pensamiento latinoamericano y la teoría de relaciones internacionales. Buenos Aires: Nuevohacer, Grupo Editor Latinoamericano.

Booth, K. \& Wheeler, N. (2008). The Security Dilemma: Fear, Cooperation and Trust in World Politics. Houndmills, Basingstoke: Palgrave Macmillan.

Bourdieu, P. (2001). Conferencia El Campo Político. El campo politico, La Paz: Ministerio de asuntos extranjeros - Embajada de Francia en Bolivia, Plural. [traducción del original de Presses Universitaires de Lyon, 2000, pp. 11-31.]

Briceño, J. (2007). La integración regional en América Latina y el Caribe. Procesos históricos y realidades comparadas. Universidad de los Andes. CODEPRE.

Briceño, J. (2016). Hegemonía, poshegemonía, neoliberalismo y posliberalismo en los debates sobre el regionalismo en América Latina. En Ardila, M. (ed), ¿Nuevo multilateralismo en 
América Latina? Concepciones y actores en pugna. Bogotá: Ed. U. Externado de Colombia.

Bull, H. (2005). La sociedad anárquica. Un estudio sobre el orden en la política mundial. Madrid: La Catarata.

Castillo, A. (2013). Perspectivas y dimensiones de una gobernanza global: el futuro de la Unión Europea como actor internacional. Revista Oasis. (18), pp. 95-114

Castillo, A. \& Brocate, R. (2013). El problema del narcotráfico en el continente americano; estrategias divergentes para una región en construcción. En Requena, Miguel (Ed.), La seguridad un concepto amplio y dinámico. $V$ jornadas de Estudios de Seguridad. Madrid: IUGM - Ministerio de defensa español.

CELAC (2011). Declaración de Caracas. "En el Bicentenario de la lucha por la independencia hacia el camino de nuestros libertadores". Caracas, Venezuela.

CEPAL (1994). El regionalismo abierto en América Latina y el Caribe. La integración económica al servicio de la transformación productiva con equidad. Santiago de Chile.

CEPAL (2010). Estudio Económico de América Latina y el Caribe 2010-2011: modalidades de inserción externa y desafios de politica macroeconómica en una economía mundial turbulenta. CEPAL.

Cox, R (1981). Social forces, states and world orders: beyond international relations theory. Millennium Jounal of International Studies, 10(2), pp.126155

CSN (2004). Declaración del Cusco sobre la Comunidad Suramericana de Naciones. III Cumbre presidencial suramericana. Cusco. Perú.

CSN (2005). Declaración de Brasilia. Comunidad Suramericana de Naciones.

CSN (2006). Declaración de Cochabamba. Colocando la piedra fundamental para una Unión Suramericana. Bolivia.

Del Arenal C. (2002). La nueva sociedad mundial y las nuevas realidades internacionales: un reto para la teoría y para la política. En Cursos de Derecho Internacional y Relaciones Internacionales de Vitoria Gasteiz, 21, 2001, Vitoria: Universidad del País Vasco, Servicio de Publicaciones.

Del Arenal, C. (2014). Etnocentrismo y teoría de las relaciones internacionales, una visión crítica. Madrid: Editorial Tecnos.

Deutsch, M. (1958). Trust and Suspicion. Journal of Conflict Resolution, 2(4), pp.265-279.

Fawcett, L. \& Serrano, M. (eds) (2005). Regionalism and Governance in the Americas. Continental Drift, Basingstoke: Palgrave.

Franzé, J. (2012). La política más allá del Estado: ¿una omisión de la violencia? Revista Española de
Ciencia Política, (29), pp. 67-83

Fukuyama, F. (1996). La confianza: las virtudes y la capacidad de generar prosperidad. Buenos Aires: Editorial Atlantida.

Gardini, G. (2011). Unity and Diversity in Latin American Visions of Regional Integration. En Gardini, G. \& Lambert, P. Latin American Foreign Policies: Between Ideology and Pragmatism. London: Palgrave Macmillan, pp. 235-254.

Giddens, A (1995). La constitución de la sociedad. Bases para la teoría de la estructuración. Buenos Aires: Amorrortu Editores.

Herrera, F. (1967). América Latina integrada. Buenos Aires, Editorial Losada.

Herz, J. (1950). Idealist Internationalism and the security dilemma. World Politics (2), 157-180.

Hobbes, T. (1997). Leviathan, Tomo 1. México: Ed. Gernika. Hoffman, A. (2002). A conceptualization of trust in international relations. European Journal of International Relations, 8(3), pp.375-401.

Hoffman, A. (2007). The structural causes of trusting relationships: Why rivals do not overcome suspicion step by step. Political Science Quarterly, 122, (2), pp. 287-312.

Holsti, O. (1962). The Belief System and National Images: A Case Study. The Journal of Conflict Resolution, vii (3), pp.244-252.

Jervis, R. (1976). Perception and misperception in international politics. Princeton University Press, 66.

Jervis, R. (1982). Security Regimes. International Organization, 36, (2), pp. 357-378.

Keating, V., \& Ruzicka, J. (2014). Trusting Relationships in International Politics: No Need to Hedge. Review of International Studies, 40(4), pp.753-770.

Keohane, R. (1982). The Demand for International Regimes. International Organization, 36(2), pp.325-355.

Keohane, R. (1988). Después de la hegemonía. Buenos Aires: Grupo Editor Latinoamericano.

Keohane, R., \& Nye, J. (2001). Power and Interdependence: World Politics in Transition, 3 ed. New York: Longman.

Krasner, S (1983). Structural causes and regime consequences. Regimes as intervening variables. International Regimes. New York: Cornell University Press.

Kydd, A. (2005-06). In America We (Used to) Trust: U.S. Hegemony and Global Cooperation. Political Science Quarterly, 120(4), pp. 619-636.

Kydd, A. (2005). Trust and mistrust in international relation. Princeton University Press.

Lagos, G. (1967). Prólogo. La evolución del pensamiento y la acción integracionistas en América Latina. En Herrera, F. América Latina integrada, Buenos Aires: Editorial Losada. 
Luhmann, N (2005). Confianza. Barcelona: Anthropos.

March, J., \& Olsen, J. (1998). The Institutional Dynamics of International Political Orders. International Organization, 52(4), p. 943-969.

Nolte, D. (2014). Latin America's New Regional Architecture: A Cooperative or Segmented Regional Governance Complex? Robert Schuman Centre for Advanced Studies Research Paper, (RSCAS 2014/89). Florence: European University Institute.

O'Neill, J. (2001). Building Better Global Economic BRICs. Global Economics Paper (66). Goldman Sachs Global Economics.

Ostrom, E. (2005). Toward a Behavioral Theory Linking Trust, Reciprocity, and Reputation. En James Walker \& Elinor Ostrom (eds.). Trust \& Reciprocity: Interdisciplinary Lessons from Experimental Research, pp. 19-79. New York, New York: Russell Sage Foundation

Rathbun, B. (2011). Before Hegemony: Generalized Trust and the Creation and Design of International Security Organizations. International Organization, 65(2), pp. 243-273.

Rojas Aravena F. (2002). Las medidas de confianza mutua y de seguridad: perspectivas desde Chile. Flacso. $17(1 / 2)$, pp. $32-43$

Rousseau, J (2013). Discurso sobre el origen de la desigualdad entre los hombres. Madrid: Ed. Delta.

Ruzicka, J., \& Wheeler, N. (2010). The Puzzle of Trusting Relationships in the Nuclear Non- Proliferation Treaty. International Affairs, 86(1), pp. 69-85.

Ruzicka, J., \& Keating, V. C. (2015). Going global: Trust research and international relations. Journal of Trust Research, 5(1), pp. 8-26.

Sanahuja, J. (2009). Del regionalismo abierto al regionalismo post-liberal. Crisis y cambio en la integración latinoamericana. Anuario de la Integración Regional en América Latina y el Gran Caribe (7), pp. 11-53
Sanahuja, J. (2012). Post-liberal Regionalism in South America: The Case of UNASUR En Florencia: European University Institute, RSCAS Working Paper 2012/05.

Sanahuja, J. (2016). Regionalismo e integración en América Latina: de la fractura Atlántico-Pacífico a los retos de una globalización en crisis. Pensamiento Propio, 21(44), pp. 29-76.

Schmitt, C. (1991). El concepto de lo político, Madrid: Alianza.

Snyder, J., \& Jervis R. (1999). Civil War and the Security Dilemma. En Walter B. F. y Snyder, J. (eds.) Civil Wars, Insecurity and Intervention, Nueva York: Columbia University Press.

TIAR (1947). Tratado Interamericano de Asistencia Recíproca. Conferencia Interamericana para el Mantenimiento de la Paz y la Seguridad del Continente. Rio de Janeiro: Brasil.

Tinbergen, J. (1965). International Economic Integration, 2 ed. Amsterdam: Elsevier.

Tokatlian, J. (1994). Componentes políticos de la integración. En Acosta, J. (Comp.): Integración, desarrollo económico y competitividad, Bogotá: Centro Regional de Estudios del Tercer Mundo.

Tussie, D., \& Riggirozzi, P. (2012). The rise of posthegemonic regionalism in Latin America. En Tussie, D. y Riggirozzi, P. (eds). The rise of post-hegemonic regionalism. The case of Latin America. Dordrecht: Sprinter.

UNASUR (2011). Tratado Constitutivo de la Unión de Naciones Suramericanas. Quito, Ecuador.

Wheeler, N. (2012). Trust-building in international relations. Peace Prints: South Asian Journal of Peacebuilding, 4 (2). WISCOMP, pp. 1-13. 